\title{
Destructive epidemic Neisseria gonorrheae keratoconjunctivitis in African adults
}

\author{
LARRY SCHWAB' AND TEFERRA TIZAZU² \\ From the 'International Eye Foundation, PO Box 2273, Blantyre, Malawi, and the 'International Eye \\ Foundation, 7801 Norfolk Avenue, Bethesda, Maryland 20814 USA
}

SUMMARY An epidemic of Neisseria gonorrheae keratoconjunctivitis in African adults occurred in Malawi in 1983. Sixteen patients, seven females and nine males, aged 18 to 60 years, were admitted to the inpatient ocular services at Queen Elizabeth Central Hospital in Blantyre from 1 February to 28 May 1983, all with severe bilateral purulent keratoconjunctivitis and concomitant venereal infection secondary to $N$. gonorrheae. Corneal melting, corneal perforation with iris prolapse, and endophthalmitis occurred in 10 eyes, of which five required enucleation. Thirteen additional eyes sustained severe visual loss secondary to corneal ulceration, leucomata, and healed corneal perforation. The route of transmission and factors of epidemicity are speculative. Because of worldwide epidemic venereal infection ophthalmologists and epidemiologists should be alert to probable sporadic $N$. gonorrheae epidemics in adults. Such outbreaks could occur elsewhere, especially in the developing world, and ocular gonococcal infection might become a significant cause of irreversible blindness.

External ocular infection secondary to the Gramnegative intracellular diplococcus Neisseria gonorrheae has been long recognised as a neonatal complication of venereally infected mothers. ${ }^{12}$ Adult gonococcal ocular infection has been considered an uncommon disorder in relation to neonatal infection. With the recent rising worldwide rates of venereal disease adult ocular gonococcal infection has been increasing. ${ }^{2.5}$

There are certainly anecdotal accounts of $N$. gonorrheae keratoconjunctivitis with corneal destruction and endophthalmitis in African adults, but thorough reports of this devasting ocular infection are scanty. In Malawi it has been reported and treated periodically at central and peripheral hospitals. An outbreak of ocular N. gonorrheae keratoconjunctivitis occurred in southern Africa in early 1983. Many adult patients with initial external purulent ocular infection and subsequent endophthalmitis, unconfirmed by laboratory diagnosis but believed to be secondary to $N$. gonorrheae, presented to hospitals other than Queen Elizabeth Central Hospital in Blantyre in 1983.

Correspondence to Larry Schwab, MD, International Eye Foundation, 7801 Norfolk Avenue, Bethesda, Maryland 20814, USA.
The following is a report of adult patients admitted to the services of the Department of Ophthalmology, Queen Elizabeth Central Hospital, with $N$. gonorrheae keratoconjunctivitis during 1 February to 28 May 1983.

\section{Patients and methods}

From 1 February to 28 May 198316 patients, nine male and seven female, were admitted as inpatients to the Department of Ophthalmology, Queen Elizabeth Central Hospital with acute, purulent conjunctivitis, clinically suspected to be Neisseria gonorrheae. In all but one case (7) the diagnosis was confirmed by laboratory determinations. The infection case unconfirmed in the laboratory behaved clinically like severe $N$. gonorrheae infection and went on to bilateral corneal perforation and iris prolapse.

The patients ranged in age from 18 to 60 years (18-60 in males, 21-31 in females) and initially sought medical attention at the general outpatient clinic of the ophthalmology services at Queen Elizabeth Central Hospital. Four patients $(2,13,15$, and 16) presented with bilateral corneal melting and perforation with iris prolapse (Figs. 1,2). In all cases 


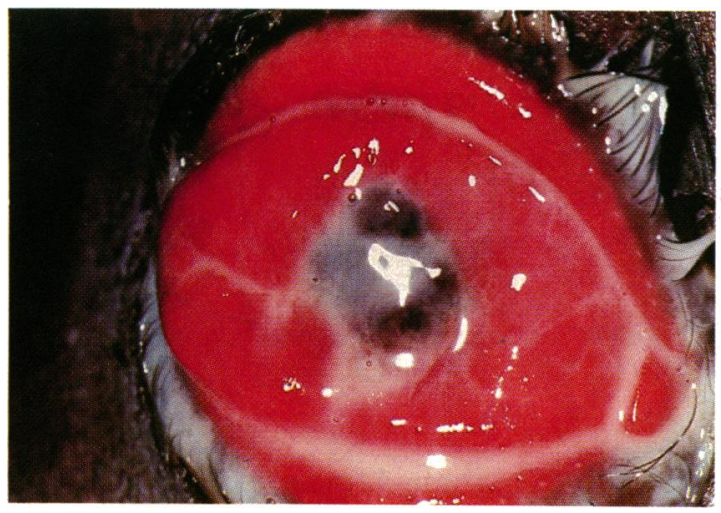

Fig. 1 Patient 2, 60-year-old male. Acute N. gonorrheae keratoconjunctivitis with corneal destruction, OS.

ocular involvement was bilateral and no patient reported any ocular disorder or injury prior to the onset of conjunctivitis.

Laboratory diagnosis was established by the presence of Gram-negative intracellular diplococci in Gram's stain and copious growth of $N$. gonorrheae on chocolate agar in 24 hours. The laboratory services were unable to assay for penicillinase-producing strains. All cultures were reported sensitive to penicillin.

Gram staining was performed on material from 15 of 16 patients and culture and sensitivity testing on material from five patients. (There are periodic shortages in culture media, which accounts for our not culturing all infections.) As previously noted, the diagnosis in one patient was established clinically, and neither culture and sensitivity testing nor Gram's staining were performed.

\section{Results}

History and physical examination revealed evidence of acute $N$. gonorrheae venereal infection in all sixteen patients.

Treatment for all the patients consisted of procaine penicillin $3.0 \mathrm{ml}$ intramuscularly for nine days; crystalline penicillin eye drops (prepared and buffered by the pharmacy, Queen Elizabeth Central Hospital) to both eyes hourly for the duration of the hospital infection; atropine $1 \%$ drops to both eyes twice daily; and tetracycline $1 \%$ ointment to both eyes four times daily.

All the patients were confined in two isolation rooms to prevent cross infection to the 50 -bed preand postsurgical ward.

Four patients were admitted with active corneal destruction, and of these eight eyes three developed endophthalmitis and were enucleated. In one patient

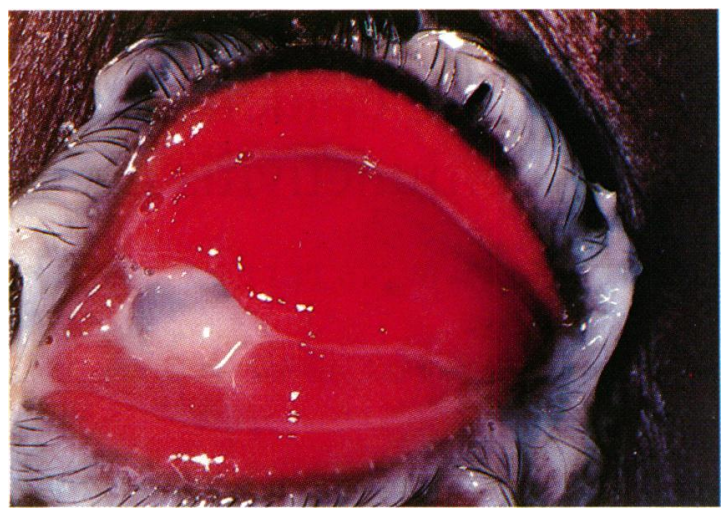

Fig. 2 Patient 13, 30-year-old female. N. gonorrheae corneal perforation and endophthalmitis, $O D$.

corneal melting and endophthalmitis developed during inpatient treatment and necessitated enucleation. Another patient sustained bilateral corneal melting and perforation with iris prolapse while undergoing treatment and required bilateral scleral (covering) patch grafts. One patient developed a unilateral anterior staplyloma, which also required enucleation. Three patients sustained bilateral leucomata severely affecting visual acuity, and another patient, in whom the left eye had been enucleated, developed an axial leucoma in the right eye.

Of 32 normally-sighted eyes prior to infection only 14 retained visual acuity of $6 / 6$ after infection had been treated and cleared. Five eyes were enucleated and seven were left with a visual acuity of $3 / 60$ or worse in the involved eye.

\section{Discussion}

The occasional adult patient with bilateral acute purulent conjunctivitis secondary to $N$. gonorrheae had been treated by the ophthalmology staff at Queen Elizabeth Central Hospital, but those nurses and clinical officers with long experience (up to 23 consecutive years) on service at the hospital could not recall a previous epidemic of this extent. Most of the adult patients who had presented in past years for treatment of this ocular infection had appeared randomly. However, several staff members had noticed that the infection had been seasonal.

This epidemic coincided with the heavy rains in Malawi's tropical weather cycle. An annual seasonal outbreak of bilateral viral haemorrhage conjunctivitis coincided with the reported $N$. gonorrheae cases, but there is no proved relationship. Thousands of patients with viral haemorrhage conjunctivitis were treated in outpatient ophthalmic departments in 
Table 1 Epidemic Neisseria gonorrheae keratoconjunctivitis with corneal destruction and endophthalmitis in Malawi in 1983. Patients who were treated on the eye services at Queen Elizabeth Central Hospital in Blantyre are presented in the chronological order by which they were admitted

\begin{tabular}{|c|c|c|c|c|c|c|c|c|c|}
\hline \multirow[t]{2}{*}{ Patient } & \multirow[t]{2}{*}{ Sex } & \multirow{2}{*}{$\begin{array}{l}\text { Age } \\
\text { (years) }\end{array}$} & \multirow{2}{*}{$\begin{array}{l}\text { Home } \\
\text { district }\end{array}$} & \multirow{2}{*}{$\begin{array}{l}\text { Date } \\
\text { admitted }\end{array}$} & \multirow{2}{*}{$\begin{array}{l}\text { Diagnosis } \\
\text { established by }\end{array}$} & \multirow[t]{2}{*}{ Sequelae } & \multirow{2}{*}{$\begin{array}{l}\text { Surgery } \\
\text { required }\end{array}$} & \multicolumn{2}{|c|}{ Visual results } \\
\hline & & & & & & & & $O D$ & $O S$ \\
\hline 1 & $\mathbf{F}$ & 31 & Blantyre & 1 Feb 83 & $\begin{array}{l}\text { Pos. Gram stain } \\
\text { Pos. culture }\end{array}$ & None & & $6 / 6$ & $6 / 6$ \\
\hline 2 & $\mathbf{M}$ & 60 & Zomba & 3 Feb 83 & $\begin{array}{l}\text { Pos. Gram stain } \\
\text { Pos. culture }\end{array}$ & $\begin{array}{l}\text { Bilateral corneal } \\
\text { perforations, } \\
\text { iris prolapse, } \\
\text { endophthalmitis }\end{array}$ & $\begin{array}{l}\text { Enucleation } \\
\text { OU }\end{array}$ & NLP & NLP \\
\hline 3 & $\mathbf{M}$ & 40 & Blantyre & 7 Feb 83 & Pos. Gram stain & None & & $6 / 6$ & $6 / 6$ \\
\hline 4 & $\mathbf{M}$ & 22 & Thyolo & 7 Feb 83 & $\begin{array}{l}\text { Pos. Gram stain } \\
\text { Pos. culture }\end{array}$ & $\begin{array}{l}\text { Bilateral } \\
\text { leucomata }\end{array}$ & & $6 / 60$ & $3 / 60$ \\
\hline 5 & $\mathbf{F}$ & 25 & Chiradzulu & 15 Feb 83 & Pos. Gram stain & None & & $6 / 6$ & $6 / 6$ \\
\hline 6 & $\mathbf{M}$ & 23 & Zomba & 17 Feb 83 & Pos. Gram stain & $\begin{array}{l}\text { Bilateral } \\
\text { leucomata }\end{array}$ & & $6 / 24$ & $1 / 60$ \\
\hline 7 & $\mathbf{M}$ & 18 & Zomba & 2 Mar 83 & Clinical diagnosis & $\begin{array}{l}\text { Bilateral corneal } \\
\text { perforation, iris } \\
\text { prolapse }\end{array}$ & $\begin{array}{l}\text { Scleral patch } \\
\text { grafts, OU }\end{array}$ & $6 / 60$ & $6 / 24$ \\
\hline 8 & $\mathbf{M}$ & 27 & Zomba & 8 Mar 83 & Pos. Gram stain & $\begin{array}{l}\text { Anterior } \\
\text { staphyloma OD }\end{array}$ & Enucleation OD & NLP & $6 / 6$ \\
\hline 9 & $\mathbf{F}$ & 30 & Machinga & 17 Mar 83 & Pos. Gram stain & $\begin{array}{l}\text { Bilateral } \\
\text { leucomata }\end{array}$ & & $6 / 24$ & $1 / 60$ \\
\hline 10 & $\mathbf{F}$ & 19 & Chiradzulu & 17 Mar 83 & $\begin{array}{l}\text { Gram stain, } \\
\text { Pos. culture }\end{array}$ & None & & $6 / 6$ & $6 / 6$ \\
\hline 11 & $\mathbf{F}$ & 21 & Mwanza & 22 Mar 83 & Pos. Gram stain & None & & $6 / 6$ & $6 / 6$ \\
\hline 12 & $\mathbf{M}$ & 25 & Chickwawa & 24 Mar 83 & Pos. Gram stain & None & & $6 / 6$ & $6 / 6$ \\
\hline 13 & $\mathbf{F}$ & 30 & Chiradzulu & 30 Mar 83 & Pos. Gram stain & $\begin{array}{l}\text { Bilateral corneal } \\
\text { perforation, iris } \\
\text { prolapse }\end{array}$ & $\begin{array}{l}\text { Bilateral } \\
\text { scleral patch } \\
\text { grafts }\end{array}$ & $3 / 60$ & $6 / 60$ \\
\hline 14 & $\mathbf{M}$ & 40 & Blantyre & 9 May 83 & Pos. Gram stain & $\begin{array}{l}\text { Endophthalmitis OS } \\
\text { leucoma OD }\end{array}$ & Enucleation OS & $3 / 60$ & NLP \\
\hline 15 & $\mathbf{M}$ & 23 & Zomba & 27 May 83 & Pos. Gram stain & $\begin{array}{l}\text { Bilateral corneal } \\
\text { perforations, } \\
\text { iris prolapse, } \\
\text { endophthalmitis }\end{array}$ & Enucleaton OS & $6 / 6$ & NLP \\
\hline 16 & $\mathbf{F}$ & 30 & $\begin{array}{l}\text { Not } \\
\text { Available }\end{array}$ & 28 May 83 & $\begin{array}{l}\text { Pos. Gram stain } \\
\text { Pos. culture }\end{array}$ & $\begin{array}{l}\text { Bilateral corneal } \\
\text { perforations and } \\
\text { iris prolapse }\end{array}$ & $\begin{array}{l}\text { Scleral patch } \\
\text { grafts, OU }\end{array}$ & $2 / 60$ & $3 / 60$ \\
\hline
\end{tabular}

NLP $=$ no light perception.

Malawi during January through April 1983. Viral haemorrhage conjunctivitis, though uncomfortable, is not known to cause corneal complications.

All the patients reported on here who presented with $N$ gonorrheae conjunctivitis and keratoconjunctivitis were clinically venereally infected with the same organism. The route of transmission in assumed to be by contamination and through inadequate hand washing and hygiene in poor socioeconomic circumstances. Interviews for detailed histories of sexual contacts and practices were not undertaken, and it is not known if ocular infection occurred from direct venereal facial contact.

One can speculate about the possible relationship of the epidemic with wetter and more humid weather conditions during the heavy rainy season and possible water contamination through face washing. Ground water is more readily available for personal hygiene during the rainy season. Likewise the occurrence of the epidemic with acute bilateral viral haemorrhagic conjunctivitis might represent a second ocular pathogen, with secondary acute infection by $N$. gonorrheae. The factors which might have produced this epidemic, however many, are undefined.

The rising rates worldwide of venereal infection in general and $N$. gonorrheae in particular should alert the ophthalmic community to prepare for future outbreaks of this virulent and tragic blinding infection.

The authors gratefully acknowledge the assistance in patient management and compilation of records of Mr William Chagona, chief clinical officer in ophthalmology, sister-in-charge Mrs Towera Chipeta, of ward 4B, and sister Charlotte Gondwe, Department of Ophthalmology, Queen Elizabeth Central Hospital, Blantyre, Malawi. 


\section{References}

1 Duke-Elder S. System of Ophthalmology. St Louis: Mosby, 1965; $8(1): 167$.

2 Chandler JW, Rotkis WM. Ophthalmia neonatorum. In: Duane T, ed, Clinical ophthalmology. Hagerstown: Harper and Row, $1980 ; 4: 3-5$.
3 Hansen T, Burns RH, Allen A. Gonorrheal conjunctivitis: an old disease returned. JAMA 1966; 195: 1156.

4 Valenton MJ, Abendanio R. Gonorrheal conjunctivitis. Can J Ophthalmol 1973; 8: 421-7.

5 Gonococcal eye infections in adults: California, Texas, Germany. Morbidity and mortality weekly report 1981; 30: 341-3. 